\title{
História de vida, projeto artístico e Teatro na escola: o PIBID Teatro na UFMG ${ }^{1}$
}

\section{Resumo}

O presente artigo apresenta o modo como temos conduzido o processo de formação do professor de Teatro junto ao Programa Institucional de Bolsa de Iniciação à Docência (PIBID) na Universidade Federal de Minas Gerais UFMG. Para tanto, trazemos a noção de história de vida, a qual tem se mostrado metodologicamente significativa para compreender como o professor acessa saberes anteriores ao seu ingresso na universidade e como revisita esses saberes confrontando-os com seu novo campo: a sala de aula. Abordamos também a noção de projeto artístico em que o professor de Teatro aproxima seus saberes do grupo de jovens, reconhecendo o potencial de cada aluno em busca de experimentos teatrais protagonizado por todos. Concluímos entendendo que ao bolsista de graduação é permitida uma formação mais completa, em que é assegurada a tutela do professor da educação básica e do professor universitário, tornando o processo de formação docente mais dinâmico com uma imersão do licenciando em seu futuro local de trabalho. E no campo de Pedagogia do Teatro há um processo de proposição-reflexão em que são experimentadas abordagens que aproximam o campo artístico do pedagógico na sala de aula.

Palavras-chave: PIBID Teatro; Pedagogia do Teatro; Formação de Professores.
Ricardo Carvalho de Figueiredo Doutor em Artes pela

Universidade Federal de Minas Gerais - UFMG. Professor da

Universidade Federal de Minas Gerais - UFMG.

Brasil

ricaredo@yahoo.com.br

\section{Para citar este artigo:}

FIGUEIREDO, Ricardo Carvalho de. História de vida, projeto artístico e Teatro na escola: o PIBID Teatro na UFMG. Revista PerCursos, Florianópolis, v. 17, n.35, p. 49 - 62, set./dez. 2016.

\section{DOI: $\mathbf{1 0 . 5 9 6 5 / 1 9 8 4 7 2 4 6 1 7 3 5 2 0 1 6 0 4 9}$}

http://dx.doi.org/10.5965/1984724617352016049

\footnotetext{
${ }^{1}$ Projeto "PIBID Teatro da Faculdade de Educação da Universidade Federal de Minas Gerais", com apoio da Coordenação de Aperfeiçoamento de Pessoal de Nível Superior - CAPES.
} 


\title{
Life history, artistic project and Theater in school: the PIBID Theatre in UFMG
}

\begin{abstract}
This article shows how we have conducted the process of training of teachers of Theatre by the Institutional Program Initiation Grant to Teaching (PIBID) at the Federal University of Minas Gerais. To do so, we bring the notion of life history which has shown a significant methodologically to understand how the teacher accesses prior knowledge of their entry into university and how revisits this knowledge confronted with your new field: the classroom. also addressed the notion of artistic project in which the drama teacher brings their knowledge of the youth group, recognizing the potential of each student in search of theatrical experiments carried out by everyone. We conclude that understanding to fellow undergraduate is allowed a more complete training that is guaranteed the protection of primary education teacher and university professor, making the teacher training process more dynamic with an immersion of licensing in their future workplace. And Theatre Pedagogy field one proposition-reflection process in which approaches are tried approaching the teaching of the artistic field in the classroom.
\end{abstract}

Keywords: PIBID Theatre; Theatre Education; Teacher Training. 


\section{Alguns pressupostos}

Desde o ano de 2007, a Coordenação de Aperfeiçoamento de Pessoal de Nível Superior (Capes) assumiu a incumbência de fomentar a formação inicial e continuada de profissionais da educação básica, estimulando e valorizando o magistério em todos os níveis e modalidades de ensino. Nesse contexto transformador, abriu-se espaço para a criação do Programa Institucional de Bolsas de Iniciação à Docência (PIBID) em âmbito nacional. Em 2009, o programa contava com 43 instituições federais participantes e alcançou, em 2014, o número de 284 instituições públicas e privadas, totalizando um número de 90.254 bolsistas, distribuídos entre coordenadores (professores universitários), supervisores (professores da educação básica) e licenciandos (alunos de graduação).

Diante da expansão do programa, a área de Teatro teve início no PIBID da Universidade Federal de Minas Gerais (UFMG) no ano de 2011, sob minha coordenação. $O$ que nos interessava naquele momento era a consolidação do campo da licenciatura em Teatro junto à Universidade e ao curso, já que em muitos momentos, ainda há uma disputa, mesmo que velada, do bacharelado em relação à licenciatura. Essa "disputa" localiza-se, muitas vezes, na grande atratividade que algumas disciplinas do bacharelado em interpretação teatral possuem em relação às disciplinas pedagógicas obrigatórias pertencentes ao currículo da formação do professor.

Grande parte de nossos alunos da graduação tiveram conhecimento/contato com o teatro de forma prática, ou seja, na condição de atores/jogadores em oficinas de iniciação teatral na escola e fora dela, principalmente. Esse fato desdobra-se no próprio sistema de ingresso do nosso curso, visto que a segunda etapa do processo seletivo no curso, após a fase do Exame Nacional do Ensino Médio (ENEM) é a prova de habilidade específica que se resume em um conjunto de questões práticas em que os candidatos realizam aulas em grupo e são avaliados em quesitos que envolvem habilidades corporais/vocais e devem apresentar um monólogo elaborado previamente.

Em 2011, tivemos então uma chamada pública no curso de licenciatura em Teatro que demorou mais de dois meses para que ocupássemos as cinco vagas para bolsistas. 
Sabemos que os fatores para o desinteresse no campo da licenciatura não são restritos à área do Teatro, dadaa desvalorização do magistério que tem sido crescente a cada ano devido a fatores como: falta de investimento no profissional, baixos salários, falta de segurança nas escolas públicas, políticas de carreira defasadas etc.

O PIBID veio, desse modo, como um grande incentivador e potencializador de discussões na licenciatura em Teatro por ser:

uma proposta de incentivo e valorização do magistério e de aprimoramento do processo de formação de docentes para a educação básica. Os alunos de licenciatura exercem atividades pedagógicas em escolas públicas de educação básica, contribuindo para a integração entre teoria e prática, para a aproximação entre universidades e escolas e para a melhoria de qualidade da educação brasileira. (GATTI etall, 2014, p. 5)

Em comunhão com essa filosofia do programa, a de possibilitar a integração teoria-prática e aproximação da universidade e escola na formação conjunta do professor, é que venho me debruçando em investigações no campo da formação docente a partir do conceito de imersão, apresentado por Maria do Céu Roldão (2007), do seguinte modo:

a formação inicial só será eficaz se transformar-se em formação em imersão, também transformadora dos contextos de trabalho, feita com as escolas, que, por um lado, coloque os futuros professores em situação que alimente o seu percurso de formação inicial e, por outro, converta as escolas, os jardins de infâncias, os contextos de trabalho em que os nossos profissionais vão atuar, em outras tantas unidades de formação que conosco, ensino superior e investigadores, construam parcerias de formação/investigação, desenvolvidas dentro da ação cotidiana da escola, transformando-a em espaço real de formação profissional permanente. (ROLDÃO, 2007, p. 40)

Nesse sentido, parto da premissa de que é na escola, produzida pelos sujeitos em suas múltiplas interações no cotidiano, que de fato temos um aprendizado do que é ser professor. 
É no próprio contexto da escola que o futuro professor construirá habilidades para lidar com a prática artístico-pedagógica (FIGUEIREDO, 2014). Em minha tese de doutorado, realizei um estudo que percorreu os caminhos da aprendizagem na constituição do professor de teatro. Para tanto, parti de minha trajetória, revisitando meu percurso formativo artístico e educacional, optando pela abordagem (auto)biográfica para compreender como pensava/construía o processo de formação dos futuros professores de teatro, quando já docente da graduação em Teatro. Optei por estudar o conceito de aprendizagem por averiguar que a conceituação de ensino não era a mais apropriada para o estudo. Notadamente, a relação entre ensino e aprendizagem mostrou-se distinta. Entendo, a partir de então, que o termo ensino está diretamente ligado ao âmbito da criação de uma circunstância explicitamente pedagógica com o propósito de se ensinar algo a alguém. No referido estudo, as experiências com o teatro não se apresentaram de forma homogênea em relações de aprendizagem organizadas, controladas e previstas, pelo contrário, manifestaram-se como plurais tais como os diversos contextos apresentados durante a tese (projeto de extensão com crianças pequenas; projeto de extensão na Educação de Jovens e Adultos; PIBID Teatro). Assim, sobrevivem modos diversos da aprendizagem em teatro na escola e da aprendizagem da docência. É por meio da participação na prática da docência (planejamento, escuta, conhecimento do aluno, estudo dos métodos etc.) que os licenciandos constituem a habilidade docente.

Nesse processo dinâmico e sutil, a aprendizagem da docência em teatro envolve mais do que técnicas. Envolve a incorporação de formas de agir-pensar, tomada de decisões, proposições e recuos. Desse modo, a docência enquanto profissão, não é isenta de esforço, pelo contrário, constitui-se em um processo intenso de imersão-participaçãoexperimentação. Por fim, o processo de aprendizagem da docência não é linear, revelando-se complexo e plural em suas formas de participação, daí a importância da aprendizagem estar recheada de momentos de ação, reflexão, observação e diálogo. A aprendizagem constitui-se, portanto, como contínua e permanente em um processo incessante de descobertas, (des)caminhos, trocas e investigação. 
Investigação essa oriunda da própria prática, ou seja, a prática teatral como pesquisa (CABRAL, 2012), proporciona uma articulação entre teoria e prática na interação entre professor e aluno. Esse compartilhamento da prática/pesquisa possibilita um desenvolvimento do campo de trabalho além de aproximar o professor novato de novos parceiros, rompendo o isolamento no início da vida profissional (TARDIF, 2011).

Com isso, é preciso compreender melhor a profissão e a profissionalização do professor na perspectiva de uma formação sólida e aberta para responder crítica e produtivamente aos desafios de formar crianças, jovens e adultos para viverem numa realidade de informações e conhecimentos processados de forma acelerada, de relações pessoais e de produção diferenciadas, características da contemporaneidade.

\section{Olhares sobre o campo da história de vida na formação do professor}

Segundo Marie-Christine Josso (2002), a narrativa de si e das experiências vividas ao longo da vida caracteriza-se como processo de formação e processo de conhecimento. Essa experiência formadora consiste na narração dos "processos de formação, de conhecimento e de aprendizagem do ponto de vista dos adultos aprendentes a partir de suas experiências formadoras" (2002, p. 34).

Penso em uma formação de professores que, aliada à história de vida dos mesmos, possibilite-os a serem protagonistas de sua própria experiência artística na escola. É preciso incentivar o sentido da inventividade do professor para que ao adentrar a instituição escolar não deixe a chama artística esmaecer. Parafraseando Luiz Fernando Ramos (2010), que propõe uma discussão acerca da poética da cena, penso que é preciso incentivar o professor, a partir de sua história de vida, a exercer sua poética docente. E se pensarmos que o exercício de uma poética própria pode conduzir o futuro professor a olhar unicamente para si, Dellory-Momberger (2011) lembra-nos que a história de vida de cada um de nós não é só nossa, tem reflexos, contaminações, interferências, uma vez que: 
as estruturas e formas de narrativa que os indivíduos utilizam para biografar sua vida não lhes pertencem de fato, eles não podem decidir sozinhos, são formas coletivas que refletem e condicionam, ao mesmo tempo, as relações que os indivíduos mantêm com a coletividade e com eles mesmos, em determinada época e no seio de uma cultura. (2011, p. 335)

A partir de então, a metodologia sobre história de vida tem me proporcionado, enquanto formador de outros professores, criar estratégias para que o repertório teatral do professor em formação que, muitas vezes é anterior ao seu ingresso na graduação, venha à tona. Hoje, com a ampliação de cursos de graduação em teatro nas universidades públicas brasileiras, vários alunos desses cursos são oriundos de grupos de teatro amador e trazem um repertório riquíssimo de aprendizagens teatrais para a universidade. Só não sei até que ponto temos tido uma atenção para a diversidade de práticas teatrais que chegam até nós, professores universitários. Diversidade que pode permitir à universidade ampliar seu debate acerca da importância da história de vida e percurso do aluno que ingressa, com diversos saberes, em um curso de graduação em teatro. Esse aprendizado compõe sua biografia e precisa ser incentivado para que este professor reconheça sua origem e valorize seus saberes anteriores ao conhecimento acadêmico, revisitando-o.

Como disse Eliseu Souza (2006), escrever sobre a experiência na formação é proporcionar ao autor (professor), através do ato de lembrar e narrar, "reconstruir experiências, refletir sobre dispositivos formativos e criar espaço para uma compreensão da sua própria prática" (2006, p. 159).

Ao conhecer mais de perto a pesquisa sobre história de vida e (auto)biografia, verifiquei que há um uso crescente dessa abordagem metodológica no campo da formação de professores no Brasil, como apontado por Belmira Bueno etall (2006) quando realizaram um estudo sobre o uso dessa metodologia no país no campo da formação de professores dentre os anos de 1985 e 2003, e constataram que houve um aumento expressivo em estudos de mestrado e doutorado que utilizaram esta metodologia para as pesquisas. 
Essa opção metodológica para as pesquisas no campo da formação docente tem relação direta com a aprendizagem da docência, como nos aponta Sandra Vasconcelos:

Os professores-formandos geralmente descobrem como se desenvolveu sua trajetória até a sala de aula, compreensão nem sempre possível no cotidiano do trabalho, quando muitas vezes o processo de ensino se torna mais importante que o processo de aprendizagem. (VASCONCELOS, 2006, p.12)

Desse modo, o mergulho na própria trajetória docente permite que o pesquisador descubra mais de si e, nesse processo, tenha mais clareza sobre suas escolhas do presente. Essa consciência pedagógica trouxe-me mais confiança para discutir, junto aos pibidianos, o quão importante é a prática docente quando exercitada no campo da formação inicial. Ou seja, tenho buscado, ao longo de minha prática docente, criar possibilidades para que o professor conheça a realidade educacional e junto a ele, propor novos desafios, mudanças, diálogos, entendendo que é na interação com outros pares, instituição, alunos e consigo próprio que o professor terá mais consciência e experiência quando estiver à frente de processos artísticos na escola. Optar por trabalhar com a história de vida é, em uma instância política da educação, romper com práticas disciplinares, que visam à massificação e homogeneização do professor, uma vez que:

Escrever sua história é tentar sobreviver, ganhar vida, fazê-la ou refazê-la e compreendê-la um pouco. Essas são operações que se situam nas fronteiras do individual, do social, do consciente e do inconsciente, do antes e do depois. (...) as histórias de vida como prática autopoiética são vistas como práticas contrabandeadas em relação às práticas disciplinares. (GASPAR, ARAÚJO E PASSEGGI, 2011, p. 02)

A seguir, apresento uma abordagem pela qual temos trilhado o (complexo) processo de formação do professor de teatro dentro do PIBID Teatro. 


\section{Quando história de vida e projeto artístico se unem para a realização do}

\section{teatro na escola}

A noção de projeto artístico visa tensionar a velha dicotomia entre professor e artista, tão difundida em cursos de Arte no ensino superior. Se, para alguns, o ranço persiste na velha história de "quem não sabe fazer, ensina", partimos do pressuposto de que a formação do professor de teatro perpassa o campo da criação, logo, esse professor será o grande detonador de processos criativos em sala de aula, seja conduzindo o grupo de alunos a criações dentro da própria sala de aula ou mesmo se apropriando de espaços na escola ou em seus arredores. Ou, como nos diz Maria Lúcia Pupo, sobre o que denominou ação artística:

(...) estaria presente a figura do artista como catalisador e revelador de questões vitais que atravessam a sociedade. (...). Assim, mais do que a perspectiva de disseminar o conhecimento do patrimônio cultural, a ação qualificada como artística daria voz a pessoas que de outro modo estariam reduzidas a se manifestarem através da voz de outros. (PUPO, 2012, p. 49)

Desse modo, o professor de teatro, dentro da ação artística, deixa de ser quem ensina um determinado conteúdo teatral para ser aquele que promove processos de aprendizagem tão diversos quanto são os quereres dos participantes do processo, incluindo o seu. Procurar, a partir de então, proporcionar que os alunos tenham voz durante todo o processo de elaboração teatral.

Vale à pena destacar que em nossa proposição, ao instigarmos os licenciandos a apresentarem seus projetos artísticos, que esses olhem para si e revisitem seus percursos artísticos, muitas vezes anteriores ao ingresso à universidade, e digam se há nesses processos de aprendizagem teatral uma consonância com o que desejam compartilhar com os jovens na escola. Olhar para si não é uma atitude narcisista, pois há um estado complementar de olhar para si no contexto em que estão inseridos, logo, devem levar em conta a escola, da qual agora fazem parte. 
Para explicitar a proposta, compartilho a experiência de Paulo Oliveira, bolsista do subprojeto PIBID Teatro que começou seu percurso de formação no ano de 2015.Paulo deu início ao trabalho como bolsista acompanhando algumas turmas de $6^{\circ}$ e $7^{\circ}$ anos do ensino fundamental. Como disse em seu relatório apresentado ao final de 2015, seu primeiro contato com as turmas foi: “Assustador. Grande parte dos alunos dificulta muito o trabalho dentro da sala de aula, sempre conversando, provocando e atrapalhando o fluxo do trabalho." Relata ainda que nas primeiras aulas quem estava à frente da turma era a supervisora e "aos poucos eu fui entrando mais no papel de professor." Essa aproximação com as turmas e com o papel da docência de forma cuidadosa e acompanhada pela supervisora foi de fundamental importância para que o pibidiano adquirisse, aos poucos, sua habilidade no trato com os alunos. A supervisora Mônica, que já está na docência há mais de quinze anos, possui saberes que foram construídos ao longo de sua trajetória e que, muitas vezes, nem se dá conta de que os possui. A segurança com que transmitia a Paulo seu conhecimento no dia a dia escolar, através da própria relação com os alunos, encorajando-o a assumir uma turma como propositor de uma experiência teatral, fez com que o bolsista se sentisse seguro de que a licenciatura era uma opção profissional e não apenas uma possibilidade de sobreviver caso a carreira de bacharelado não fosse promissora.

Ressalto que Paulo, antes de seu ingresso no PIBID, já havia se formado no curso técnico de atores no Centro de Formação Artístico (CEFAR) do Palácio das Artes em Belo Horizonte. Esse curso técnico, segundo o próprio bolsista, lhe possibilitou conhecer meandros do fazer teatral que Paulo pôde incorporar em suas aulas na escola municipal. Naquele curso, Paulo identificou que sua linha de trabalho no teatro aproximava-se do teatro-dança, incorporando essa técnica em seu treinamento como ator.

Ao longo do primeiro semestre de 2015, o pibidiano foi conhecendo as turmas e identificou-se com a turma do $6^{\circ} \mathrm{A}$, cujos alunos eram os mais jovens e dispostos às atividades teatrais. Como o nosso projeto para aquele ano era o trabalho com máscaras, Paulo procurou saber dos alunos qual texto poderia ser o mote para o trabalho. Foi daí que chegou ao livro "Diário de um banana”, de Jeff Kinney (2008), que por tratar do diário de um menino com idade próxima à dos adolescentes, tinham interesse na 
temática e contribuíam com suas experiências de vida. As aulas com essa turma aconteciam duas vezes por semana, totalizando duas horas - o que favoreceu um trabalho mais aprofundado.

Para engrossar a discussão do livro e a realidade dos alunos, Paulo levou a animação The DamKeeper, sobre o tema do bullyingque foi recebido com entusiasmo e identificação por eles. Após essa etapa, Paulo ainda propôs improvisações em que fossem discutidas situações de bullying sofridas pelos jovens. As máscaras que já estavam moldadas foram ornamentadas com a temática discutida e os personagens criados pelos alunos. A ênfase no trabalho corpóreo, objeto de estudo e conhecimento de Paulo, foi a linha mestra da proposta cênica. O protagonismo dos jovens e o interesse pela temática abordada foram elementos de fundamental importância para o trabalho bem sucedido do jovem professor.

Nossa intenção era a de que as turmas pudessem se apresentar umas para as outras e foi, então, que conseguimos levar os alunos para se apresentarem fora do espaço escolar, no prédio do curso de Teatro da UFMG, onde além de haver uma sala com recursos de iluminação havia também o entusiasmo de sair da escola e se apresentar fora do espaço cotidiano.

Foi então que, na primeira semana de dezembro de 2015, os alunos da Escola Municipal Aurélio Pires foram para a UFMG apresentar o resultado de um processo de criação para seus colegas e também para estudantes de teatro da universidade. Puderam reconhecer o espaço e ensaiar no local, além de conhecer o prédio do Teatro e as instalações do curso de graduação. Uma manhã de muita euforia, frio na barriga e protagonismo dos jovens ficou marcada em nós.

\section{Algumas retomadas a guisa de conclusão}

Destaco que umas das maiores relevâncias do PIBID é a parceria explícita do professor da educação básica com o professor universitário no processo de coformação do futuro professor da educação básica. A investidura no professor da educação básica para que aproxime sua experiência junto à universidade é um modo de mostrar a esse 
profissional o seu potencial intelectual e prático no campo da docência. Ao professor da universidade é permitida uma retomada com a educação básica, podendo revisitar dia a dia seus conceitos e, portanto, sua prática como formador de outros professores já que está imerso no cotidiano escolar novamente. Ao bolsista de graduação é permitida uma formação mais completa em que é assegurada a tutela do professor da educação básica e do professor universitário, tornando o processo de formação docente mais dinâmico com uma imersão do licenciando em seu futuro local de trabalho, diferente dos estágios curriculares ${ }^{2}$.

A noção de história de vida tem se mostrado relevante para que resgatemos a experiência teatral oriunda em outros espaços formativos, oportunizando ao jovem professor em formação que reconheça aquele espaço enquanto local dotado de potencialidades e ampliando sua noção de teatro - uma vez que a universidade, em muitos momentos, ignora os saberes que estão fora do seu currículo.

O professor de teatro em formação que se descobre como desencadeador de processos artísticos na escola pode, em diálogo com seus alunos, dar vazão a experimentos em que são criadores.

A aposta no protagonismo do jovem professor em formação para que conheça desde cedo os dilemas da educação básica e, de forma compartilhada com professor supervisor e professor coordenador, possam buscar novas alternativas para a educação na contemporaneidade, gerando rupturas e trazendo mais vida ao sistema escolar.

\section{Referências}

BUENO, Belmira et al. Histórias de vida e autobiografias na formação de professores e profissão docente (Brasil 1985 - 2003). Educação e Pesquisa, São Paulo, v.32, n.2, p. 385 410, maio/ago. 2006.

CABRAL, Beatriz. Teatro em trânsito: a pedagogia das interações no espaço da cidade. São Paulo: Hucitec, 2012.

\footnotetext{
${ }^{2}$ Há grande distinção entre o PIBID e os estágio curriculares, das quais destaco: estágio é disciplinar e requer um número fixo de horas a serem cumpridas na escola; pouco ou nenhum contato do professor coordenador de estágio com o professor da educação básica; entre outros aspectos.
} 
DELORY-MOMBERGER, Christine. Fundamentos epistemológicos da pesquisa biográfica em educação. Educação em Revista. Belo Horizonte. v.27, n.01, p.333-346, abr./2011.

FIGUEIREDO, Ricardo Carvalho de. Percursos de aprendizagem da docência em teatro a partir do próprio ato docente. 2014. 216 p. Tese (Doutorado em Artes) - Universidade Federal de Minas Gerais, Escola de Belas Artes, Belo Horizonte, 2014.

GASPAR, Mônica; ARAUJO, Maria de Fátima; PASSEGGI, Conceição. Memorial - gênero textual autobiográfico. In: SIGET - SIMPÓSIO INTERNACIONAL DE GÊNEROS TEXTUAIS, VI, Natal, 2011, Anais... Natal: SIGET, 2011. p. 01-13.

GATTI, Bernardete et al. Um estudo avaliativo do Programa Institucional de Bolsa de Iniciação à Docência (Pibid). São Paulo: FCC/SEP, 2014.

JOSSO, Marie-Christine. Experiência de vida e formação. Lisboa: EDUCA, 2002.

KINNEY, Jeff. Diário de um banana. Trad. Antonio de Macedo Soares. Cotia, SP: Vergara \& Riba Editoras, 2008.

PUPO, Maria Lúcia. Alteridade em cena. Sala Preta, v. 12, n.1, p. 46-57, un., 2012.

RAMOS, Luiz Fernando. Pós-Dramático ou Poética da cena? In: GUINSBURG, Jacó; FERNANDES, Sílvia. O Pós-Dramático: um conceito operativo? São Paulo: Perspectiva, 2010. p. 59-70)

ROLDÃO, Maria do Céu. Formar para a excelência profissional: pressupostos e rupturas nos níveis iniciais da docência. Educação e Linguagem. UFRGS. Ano 10, n. 15, p. 18-42, jan./jun, 2007.

SOUZA, Elizeu. A arte de contar e trocar experiências: reflexões teórico-metodológicas sobre história de vida e formação. Revista Educação em Questão. Natal/RN: EDUFRN, v. 25, n.11, jan./abr. 2006.

TARDIF, Maurice. Saberes docentes e formação profissional. 12 ed. Petrópolis, RJ: Vozes, 2011.

VASCONCELOS, Sandra Maia Farias. Professor: que história é essa? Revista Educação em Questão. Natal- RN: EDUFRN, v. 25, n. 11, jan./abr. 2006. 
Recebido em: 23/02/2016 Aprovado em: 04/08/2016

Universidade do Estado de Santa Catarina - UDESC

Centro de Ciências Humanas e da Educação - FAED

Revista PerCursos

Volume 17 - Número 35 - Ano 2016 revistapercursos@gmail.com 